the Sarracenia, like some animals, can feed upon carrion and thrive upon it.

In instances in which experiments have been made with fresh, raw beef or mutton, the meat has been covered in a few hours with the secretions of the leaves, and the blood extracted from it. There is, however, one difference between the digesting powers of the leaves when exercised upon insects or upon meat. Even if the bodies of insects have become putrid, the plant, as has already been stated, has no difficulty in assimilating them ; but as regards meat, it is only when it is perfectly sweet that the secretions of the leaves will act upon it.

The Pitcher plant undoubtedly derives its principal nourishment from the insects it eats. It, too-unlike most other carnivorous plants, which, when the quantity of food with which they have to deal is in excess of their powers of digestion, succumb to the effort and die-appears to find it easy to devour any number of insects, small or large, the operation being with it simply a question of time. Flies, beetles, or even cockroaches, at the expiration of three or four days at most, disappear, nothing being left of them save their wings and other hard parts of their bodies.

The Sarracenia is, indeed, not only the most voracious of all known species of carnivorous plants, but the least fastidious as to the nature of the food upon which it feeds.

W. C. M.

\section{THE ECLIPSES OF AUGUST, 1886}

$\mathrm{T}$ T has been before stated in NATURE that the total solar 1 eclipse of August 28-29 next year can be most favourably observed on the west coast of Africa near Benguela. In a recent number of Science Mr. Skinner supplies a valuable account of the local conditions, which we here reprint :-

"Benguela is about 400 miles south of the mouth of the Kongo, and about 200 miles south of the mouth of the Koanza. The climate of the lowlands bordering the coast near Benguela is fatally unhealthy for strangers, making it compulsory, on the score of prudence, for an observing party to penetrate the interior sufficiently to attain the mountainous highlands which lie not far inland.

"The American Board of Commissioners for Foreign Missions has for some three years occupied two mission stations in this region-viz. Bailundu, about I 33 miles eastward from Benguela, and Bihe, about 70 miles southeast from Bailundu. Through the courtesy of Rev. Judson Smith, D.D., secretary of the American Board, and Mr. Frederick A. Walter, secretary of this west central African Mission, I have received definite statements of some of the precautions necessary, and some of the difficulties to be encountered by an observing party locating in this region. I will give in brief the points with which Mr. Walter favours us.

"Dangers to the person from savages are not to be apprehended. The climate of Bailundu and vicinity is exceedingly salubrious. During a residence of nearly three years, Mr. Walter and his family have experienced no illness to be ascribed directly to the climate, but in every case to overwork, over-exposure to the sun, or want of proper food.

"The difficulties in reference to transportation are considerable. Transportation is done entirely by men; waggons and animals cannot be used. The gross weight for a carrier is from 65 to 70 lbs. ; commonly it does not exceed 58 lbs. Packages, either bales or boxes, should be of about the following dimensions:-14 inches by 9 inches by 30 inches, or, if more convenient, 16 inches by io inches by 24 inches. No single package should exceed 18 inches in width by 10 inches in depth. Pieces not exceeding $60 \mathrm{lbs}$. in weight, though 8 or Io feet long, can be carried by a single carrier.

"As to means of subsistence, an observing party must bring all their supplies with them, as it is essential to the health of newcomers that they should live on food to which they are accustomed. The time required for a round trip of a caravan from Bailundu to Benguela may be stated as one month to six weeks.

"Mr. Walter states that the chances for clear sky at the time of the eclipse are very favourable.

"It may be stated that the land rises very abruptly as onc leaves the coast from Benguela, and in a few miles attains a very considerable altitude, and throughout these highlands the climate is very healthful."

\section{INTERNATIONAL INVENTIONS EXHIBITION}

SELF-ACTING or automatic machinery has made wonderful strides of late years, and its progress in the special department of watch-making cannot be more advantageously studied than in the beautiful display of machine tools now exhibited by the American Waltham Watch Company at South Kensington. We think that a few remarks with reference to the functions of these tools may be of service to the readers of NATURE when viewing the collection. The machine tools are all labelled, and can readily be identified.

(I) A screw-making machine.-This machine is engaged in producing watch jewel screws; the size of the screws may be appreciated when we state that it takes more than 8500 to weigh one ounce troy. Lengths of wire are transformed into these tiny screws in the following manner. The machine is fed with the wire through a hollow mandrel, the wire is seized and rotated rapidly, a movable cutter is brought against it, and immediately the body of the screw is turned. Two dies are at hand which attach themselves, and they cut the thread; on reaching the limit of their cut, they pull out the wire a distance, the thickness of the screw head, for hitherto the wire has only projected the length of the body of the screw through the mandrel head. The dies disengage themselves, and a second cutter cuts off the screw at its junction with the mandrel head. There is an alternating arm, the most conspicuous part of the machine: this takes possession of the screw as it is cut off, and, carrying it to a different part of the machine, holds the head against a small circular mill, where the notch is cut. The screw is now finished, and is discharged into a magazine by a kind of ramrod. The machine turns out 4000 screws a day, and indeed the successive operations go on with so much rapidity, that it requires some practice to follow them. It is to be noticed that when the dies are cutting, the wire is stationary, and the machine then quickens its motion to save time. When the dies pull forwards, the chuck holding the wire opens simultaneously. Copious streams of oil are supplied to wash away the shavings, and the oil after being used once, escapes into reservoirs from whence it is automatically pumped up again. The different parts of the machine are regulated almost entirely by cams, the dies by a very elegant arrangement of opposing toothed sectors.

(2) A machine for cutting off dial feet-i.e. attachments If this machine stood alone it would be interesting, but it is overshadowed by its neighbours.

(3) A machine for roughing out staves or pinions.-This is similar in some respects to the screw-making machine. Lengths of wire are fed through the mandrel, and a cutter shapes one end of the staff or pinion, giving it a male centre. It is then cut off, but the other end has to be shaped with its male centre too. Again we have an alternating arm, which carries the pinion away and places it in a very similar mandrel on the other side. So soon as it is gripped it begins to rotate; a cutter comes and shapes the unfinished end with its male centre. When done it is discharged into a magazine, as the tiny screws were.

(4) This is a machine for trueing down the staves or 
pinions roughed out in (3). Like (2) this is a simpler machine, but worthy of attention. The roughed-out pinions are here turned true upon their own centres. Notice that when the tool has turned off the necessary amount it stops of itself, till started for a fresh piece.

(5) A pinion-polishing machine.-The polisher is driven to and fro by crank motion. After a sufficient number of rubs have been given the pinion turns automatically and presents a fresh face to the polisher, till all the leaves are done. The other side of the stand shows us a lathe requiring no special explanation.

(6) An automatic machine for cutting pinions.-In this is exhibited an elegant arrangement for bringing a succession of cutters into play. The principle, however, is very much better illustrated in the scape-wheel engine that follows; we therefore defer explanation.

Alongside of this machine is another for cutting the bevelled wheel teeth for keyless work.

(7) A scape wheel tooth-cutting engine. The scape wheels to the number of sixty are threaded upon a kind of split spindle, which passes through the spaces around their arms, and holds them firmly. The spindle with the wheels around it looks like a solid rod of brass, and the cutter acts transversely so as to scoop a groove through all the sixty at once. Owing to the peculiar shape of tooth and the degree of finish necessary, seven different cutters are required. The actions are as follow:-The spindle being placed in position, the first cutter operates. When it has made one groove the spindle turns; it makes another, and another, in all 15 , which corresponds to the number of teeth. A sudden change now happens-the first cutter is diverted, and a second takes its place This cutter works through all the fifteen spaces, and then the next supersedes it, until all have had their turn and the wheel is finished. We understand that the whole sixty wheels are cut in about twenty minutes.

(8) Another polishing machine, of somewhat similar design to (5).

(9) On a counter opposite to the main stand is shown an interesting instrument for determining the strength of watch-balance springs. In this the differential principle is employed, the spring to be tested being measured against one of known force, and the number of degrees the latter is deflected registered. The springs are sorted into compartments corresponding to these numbers.

There are two other tools not working at present, but still of considerable interest. The first is supplementary to (9), which only gives the strength of the spring within certain limits. There is a normal balance with spring attached, and the balance and spring to be tested are mounted on an arm alongside of it. A lever sets both balances vibrating simultaneously, and it is easy to perceive in a few seconds whether their vibrations are synchronous or not. The other tool is automatic, and is for the purpose of drilling and tapping the screw-holes in compensation-balances. These holes are placed at irregular distances, as experience has suggested. By means of a divided plate the machine automatically finds these intervals. A very pretty feature will be noticed when the machine is drilling-viz. that the drill is withdrawn occasionally by the machine to free the cuttings, just as would be done by a workman.

\section{Henry Dent Gardner}

\section{THE NICE FLOATING DOME}

$\mathrm{W}^{\mathrm{E}}$ have already (NATURE, vol. xxxii. p. 62) referred to the floating dome for the great equatorial of the Nice Observatory of $M$. Bischoffsheim. We give now an illustration from $L a$ Nature, which shows the details of the annular floater. The entire dome is supported on the annular floater situated at its base. The floater, of hollow metal, swims in a circular caisson containing water holding saline matter in solution. When the dome is in the position of normal buoyancy, the only friction which opposes its movement of rotation is the friction inside a liquid body, and consequently is extremely feeble, notwithstanding the great weight of the moving mass. Experiments prove that one man can easily set the dome in motion with his hand. The floater of the dome is open above like an undecked boat; it has a rectangular section of $1.50 \mathrm{~m}$. in height by $095 \mathrm{~m}$. in breadth. Its walls are bound together by rivets of steel.

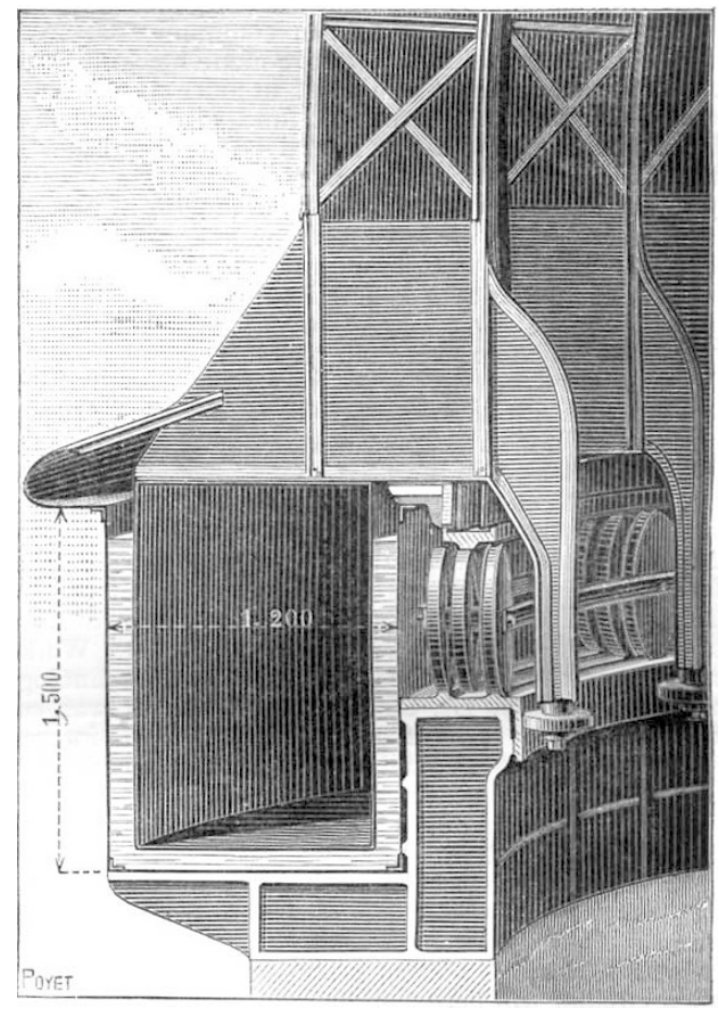

The annular caisson, which receives the floater and the liquid, has a rectangular transverse section; its height is $\mathrm{I} .50 \mathrm{~m}$., and breadth $\mathrm{I} 20 \mathrm{~m}$. The latter dimension thus exceeds the breadth of the floater by $0.25 \mathrm{~m}$., which gives a lateral play of $0.125 \mathrm{~m}$. in the inside and $0.125 \mathrm{~m}$. at outside between the floater and the caisson. Finally, the caisson rests on thirty-six strong cast-iron supports, distributed at equal distances over the upper part of the mason-work of the tower.

\section{A NEW ENDOWMENT FOR RESEARCH}

$\mathrm{T} \mathrm{T}$ is usually the case that private endowments for public purposes are made subject to narrowing restrictions, and then it too often ensues that with the lapse of time the very object of the gift is defeated by the restrictions - the letter kills the spirit. It must therefore be a matter of congratulation when a great public donation is left as free as compatible with the general object for which it is made. This is remarkably the case with a noble and munificent endowment established by Mrs. Elizabeth Thompson, of Stamford, Connecticut-an American lady well known for her public benefactions. Her long experience with churches and various charitable enterprises had led her to question whether the money spent in them achieves the greatest possible good. She finally reached the conviction that knowledge is the real source, the impelling power, of human progress, and it 